\title{
AT PLAY IN THE COSMOS: THE THEATRE AND RITUAL OF NICOLÁS NÚÑEZ ${ }^{23}$ \\ Deborah Middleton
}

In 1975, Nicolás Núñez founded the Taller de Investigación Teatral - Theatre Research Workshop (TRW) - under the auspices of the National University in Mexico City (UNAM). Throughout its history, the TRW has functioned as a center for research in the fields of both theatre and ritual. Working closely with Helena Guardia, and other members of the group, Núñez has explored the connections between theatre and ritual by researching within a number of traditional and contemporary performance conventions. In particular, the group has worked extensively with indigenous Mexican traditions, but this heritage has been considered through a prism of performance forms from other cultures. For example, in 1986, members of the group traveled to India to study for one year at the Tibetan Institute of Performing Arts to examine the theatre and rites of a culture they considered spiritually close to their own. Their research has also taken them to the heart of Western theatre drawing from Stanislavski, studying with Strasberg, working for a year with Grotowski as 'co-responsibles' during his Theatre of Sources period. From each of these ventures, Núñez has sought guidance for the creation of a ritual theatre - a theatre that is inspired by sacred practices but transplants those practices into a secular theatrical context. Guided especially by the indigenous performance traditions and philosophies of the Náhuatl Indians of Mexico, Núñez seeks a theatre that may serve as a vehicle through which participants can experience the ancient tradition of offering their hearts to the sun-literally making one's own sun, the heart's sun, rise.

Núñez published Teatro antropocósmico in 1987. This record of the TRW's many adventures outlined the theatrical phenomena to which their research

23 Originally published in The Drama Review 45, 4 (T172), Winter 2001 
had brought them: 'anthropocosmic theatre'-a theatre of the human in the cosmos. [...] Núñez's book describes the TRW's work as 'devices of "participatory theatre" which give back to our organism its capacity to be the echo box of the cosmos' (p. 7 above). The centrality of the cosmos within Núnez's theatre is a direct result of the group's research into their pre-Hispanic cultural roots. The heritage they uncovered from the ancient peoples who built pyramids, designed calendars, and studied the universe was a religio-philosophical tradition that aligned the hearts of men and women with the life of the stars. Accordingly, the theatre that Núnez and his group have evolved is designed to put participants in touch with a sense of their cosmological context. This is approached through recourse to ritual practices believed capable of altering consciousness and perception, and through mythological imagery that evokes concepts of nature and the forces of nature. If this seems like an ambitious objective, then it is one that Núñez, seeking a performative tradition for contemporary Mexicans, found irresistible.

Participation is central to the work of the TRW, and is seen as the key to investing theatrical structures with the potentials of ritual. Accordingly, the work consists largely of interactive 'dynamics', structured sequences of psychophysical actions in which participants play an active part and through which they may access altered states of experience. While a particular dynamic may form the basis for a large public event, such as Citlalmina (1988), the dynamics are more generally available to participants through the weekly open sessions of the TRW at UNAM's theatre space, Casa del Lago, in Chapultepec, Mexico City, and through pedagogical workshops given at home and abroad. Since 1993, Núñez has carried out seven workshops in Britain; ${ }^{24}$ my attendance at these workshops, along with my involvement in Núñez's work in Mexico during three research trips to the country, form the basis of this analysis.

In addition to the workshops and dynamic-based public events, the TRW also produces theatrical performances in which participants may play a more

24 At the time of publication, Núñez has delivered 12 workshops and 4 productions in the UK. 
or less conventional spectator's role. In these works, the objective is essentially the same as that of the dynamics: in Núñez's words, 'to involve the spectator in the raising and focusing of energy, and in a journey of self-knowledge' (p. 3 above). Productions such as the TRW's Cura de espantos (Cure for Fears, 1998) incorporate both aspects of the work within a dramatic structure that effectively combines a traditional actor-spectator relationship with full audience participation. Through careful structuring, spectators are gently guided between two different roles: witnesses to the theatrical presentations, and active participants. Having witnessed and reflected, participants are typically offered the opportunity to engage with a holistic ritual activity within the confines of the theatrical event.

Núñez has forged a theatre that attempts to provide an active arena for those individuals who seek personal individuation, communitas, or the experience of the sacred dimension in their everyday lives. The TRW carves out a sacred space in the context of an urban, cultural institution. To some extent, the work may function as a kind of 'performative religion' (Grimes [1982] 1995: 266). However, Núñez is particularly careful not to invest the actions and experiences of the dynamics with any overt ideology. The TRW professes no particular belief system; the search for 'meaning' and the imposition of defining conceptual frameworks remain the responsibility and personal quest of the individual participant. In place of ideology, the Taller offers experiences; ludic, dramatic, psychophysical activities anchor the participant quite firmly in the realm of theatre, but also support the transformative potential of ritual. The TRW specializes in play, but these are 'serious games', and like all games, when played seriously, they may have real consequences (Núñez 1999).

Núñez's theatre consciously seeks to explore and exploit the connections between theatre and ritual in order to emphasize the transformative potential of performative experience - to use theatre as a secular framework for ritual structures. In Victor Turner's definition, ritual is:

a transformative performance [...] transforming social and personal life- crises $[. .$.$] into occasions where symbols and values representing$ 
the unity and continuity of the total group were celebrated and reanimated. [...T]hrough its liminal processes, it holds the generating source of culture and structure (1983: 223).

Núnez's theatre attempts to create transformative rituals that respond to life crises within the individual. Indeed, his pedagogical workshops and performances are frequently introduced with a note to participants that the work is designed for those in personal crisis; like Grotowski's theatre and paratheatre, this work is intended for an elite defined not by social status, but by spiritual or emotional compulsion. The work of the TRW is designed to effect psychological, physiological, and spiritual change through the dissolution of negative psychophysical modes of behavior, and through the embodied experience of life-affirming symbols and processes. It seeks both to enable participants to generate their own personal mythologies, and also to assist in a wider campaign to recover indigenous cultural symbols.

Like many theatremakers who share the impulse toward ritual, Núñez has been influenced by shamanism. Sometimes familiar to those in industrial societies via the popular and academic literature which is available on the subject, shamanism provides an appealing model of the performer as healer, myth-maker, and 'technician of the sacred', a model that many Western practitioners have sought to appropriate by means of literary investigation. In Mexico, however, shamanic and other ritual practices persist as functioning rites or cultural forms in a number of indigenous traditions. For the TRW, the model of the shaman - or the Huichol mara'akame - has been both a conceptual ideal and a source of practical research and training: a working model. When the group infuses their theatrical performances with ritual structures, they do so with the full permission of the relevant tradition's authorities, having been first initiated into those practices within their religious contexts. Nevertheless, the significance of the work lies less in its authenticity with regard to traditional practices, and more in its ability to generate new ritual models. The central work of the TRW has been the search for ways to safely and effectively transplant religious rituals into 
contemporary secular cultural forms, maintaining their psychophysical and numinous potential beyond the matrices of their belief-system of origin.

Núñez's theatre follows the shamanic model particularly in its methods of training participants in techniques of raising energy, accessing and leaving alternate states of consciousness at will; in the imageries of descent and ascent, and of animal guides (nagual); and in the use of certain energetic bodily positions and actions. In Núñez's secular and theatrical context, however, there is no attempt to replicate shamanic belief systems, nor is it necessary for participants to believe in a spiritual realm. Núñez deliberately refrains from placing the participant's experiences in explanatory contexts, in order that the work can be as free as possible from an imposed ideology. The participant is free to interpret her own experience in the light of belief in a God, a spirit world, Jungian psychology, or creative visualization. Thus, the work might be seen as an arena in which participants encounter, explore, and generate their own imaginal, and perhaps spiritual, inner worlds within the framework of their personal, and private, belief systems.

\section{The Dynamics}

Núñez's research within the field of ritual and psychophysical practices (particularly among the Huichol and Náhuatl peoples of Mexico, and in contemporary bicultural traditions such as conchero dancing ${ }^{25}$ ) have enabled him to develop a series of structures through which personal ritual contact with the self and the cosmos may be possible. He calls these structures 'dynamics' because their primary effect is upon the energies within an individual, a group, and the spatial surroundings.

To date, there are 21 dynamics, ${ }^{26}$ each with a different psychophysical emphasis, a different imaginal content, and each utilizing the 'tools' of the

25 The concheros are dancers who are members of highly organized groups, the aim of which is to preserve the traditional ritual dances of pre-Hispanic Mexico, and to perform at seasonal festivals.

26 Please see pp. 225 - 227 below for a discussion of the number of dynamics at the time of going to press. 
TRW in different ways. Each dynamic consists of two scores: an external score of physical actions and an internal score of meditations and focusing images. In practice, these two scores work closely together, each facilitating the other - their interplay being the essential aim. Each dynamic is internally supported by a mythological image from the pre-Hispanic pantheon that acts as a focusing device and provides a conceptual — even philosophicalcenter. For example, we have Quetzalcóatl, the Feathered Serpent; Tonatiuh, the Sun God; and Citlalmina, the Archeress who shoots arrows at the stars.

Primarily, the dynamics have been developed as devices for actor training. The ritual aspects of the work encourage participants toward a profound self-knowledge through tools that develop mental, physical, and energetic discipline, and through the development of skills for accessing and leaving altered states of consciousness at will.

Through practical research, the members of the TRW have discovered what Núñez considers to be the key features of the dynamic: continuous movement, continuous mental focus on one's experience, changing rhythms, and alternation between tension and relaxation. These are the underlying principles within each dynamic, discovered through practice and through careful attention to the effects of the dynamic as experienced subjectively by group members. Thus, a dynamic consists of a continuous sequence of alternating psychophysical actions throughout which participants remain in continual motion. These actions include slow walking, whirling, 'contemplative running', the corporeal alphabets of certain sacred dances (notably from the Mexican conchero and Tibetan monastic traditions), and movements - such as running backwards with eyes closed - which are designed to 'deprogram' daily behavior patterns. These tools are juxtaposed in such a way as to allow their differing rhythms and energetic demands to create dynamic frictions within and between participants. At all times, the participant should work with strong attention, with a constant focus of mind on body, and continually struggling against the dispersal of energies. 
These three challenges draw the participant into an experience of intense presence within the moment - what Núñez calls 'the actualized instant'. For Núnez, it is precisely this concept that forges a navigable bridge between the worlds of theatre and ritual (1996b) [see Figure 12 on p. 272 below]. He sees the relationship between the two as centered upon an essential axis, a common dependency on the actualized instant; that is, at the center of each is 'the moment'. Both theatre and ritual are activities which take place in a spatial and temporal terrain and which require the 'enlivening' of time through focus and action, full psychophysical presence in what Stanislavski called 'the here and now'. Núñez has identified Stanislavski's here and now as an 'archaic mechanism of rite'; a 'vehicle to arouse another reality' (p. 54 above). He sees in Stanislavski's work the rediscovery of the essential element that allows theatre to cross from the profane to the sacred sphere. Being fully present in the present moment is both the actor's means of energetic, emotional, imaginative power and the hierophant's means of accessing other levels of consciousness, aided by the faith and imagination of the Stanislavskian 'as if', itself a door into other realms of reality. Making contact with the here and now is, by necessity, making contact with oneself, and with one's experience. I Wayan Lendra reports that Grotowski used to assert that one should 'see that you are seeing and hear that you are hearing' (1991: 126).

Access to enlivened time, to full experience of the moment, is built upon a foundation of training techniques, whether for the actor or the hierophant. In many cultures today, actors use their techniques for commercial and profane reasons; hierophants traditionally use theirs for sacred and cosmic purposes. Yet, as Richard Schechner has shown and discussed, the hierophant's techniques, under particular circumstances, may in fact relate us not to the cosmos but to commerce (1988: 106 - 152). Likewise, as Grotowski's theatre exemplified, the actor may relate us to the sacred dimension - the nonordinary modality of numinous human experience. It is Núñez's intention to find theatrical games that will allow ordinary participants to access the realm of the sacred. 
Núñez describes the struggle to remain actively in the present moment as 'epic' - not in a Brechtian sense, but rather to connote an effort of impressive, even 'heroic', proportions (1996b). The epic effort involves a struggle with oneself: overcoming one's limitations and obstacles; becoming, as Núñez terms it, the 'warrior' in one's own personal battle (1993). During the contemplative run, for example, the battle is against the temptation to give in to the physical and mental discomfort that arises, for most people, from running for extreme periods of time. So, too, the ritual dance, Citlalmina, is a 'warrior dance':

You are like a warrior, and you are going to give your battle, you are not going to dance, you are going to fight. And this fight is against the ego. [...Y] ou have to conquer your body, you have to conquer your mind, and then you might try to conquer, maybe to know, your spirit. But if you do not conquer your body and if you do not conquer your mind, you will never find out what to do with your spirit (Núñez 1993).

Unless a participant encounters this opportunity for personal effort within the practice, he will achieve only physical exercise through the dynamics. When the work is performed with an epic psychophysical struggle to inhabit the moment and to overcome weaknesses of will, then energy and strength are invoked in the participant. Further, the experience teaches an important life lesson: through hardship and effort we encounter the best in ourselves; through going down into the darkness, we give ourselves the possibility of emerging into light.

In Turner's model of social drama (1995: 8-10), interpersonal conflicts provide the pivotal points in the life of a community and lead to reflexivity, redressive action, and either reintegration or recognition of the need for change. In the dynamics, the conflicts that arise are within the individual psyche (although they may, at times, be aroused by interpersonal relations through the experience of working intimately with a partner or being part of a group). It is the epic struggle that is instrumental in urging the 
participant toward self-reflection and a redressive process. Without the latter, a participant would feel only a sense of inadequacy, perhaps despondency or frustration. However, the dynamics and the public performances are designed to carry willing participants into an arena in which they may initiate their own process of transformation. Significantly, in Turner's model the redressive phase of social drama includes ritual, among other processes. The ritual process, according to Van Gennep (1908) and Turner, is comprised of three phases, each of which may well involve performative means to realize its function. These phases are separation, transformation, and reaggregation. The dynamic as a whole may be seen to fit this pattern. Separation from daily life is begun with the formation of a circle, suspension of social roles (silence, alternation of males and females in circle), and frequently the use of a vibratory chant to charge the space and internalize the participants' attention. The closing sequence of each dynamic restores the participant to the circle, to contact with others, and to a sense of the outside world. The energy and focus that has been generated is released, and frequently a yogic 'balancing' position is assumed.

The central actions of the dynamic are liminoid and ludic, and may involve contact with, or enactment of, 'sacred' or unconscious materials. Within this structure, participants may make use of the supporting actions and images of the dynamic, as well as other personal imagery that might arise, in an attempt to overcome personal inner conflicts.

Turner describes liminality as:

a fructile chaos, a fertile nothingness, a storehouse of possibilities, not by any means a random assemblage but a striving after new forms and structure, a gestation process, a fetation of modes appropriate to and anticipating postliminal existence (1990: 12).

In the dynamics, there is typically a certain 'looseness' of form; participants are not given detailed formal instructions but rather find their own way to perform the actions. That is, they seek out their own means of utilizing both 
personal imagery and the imagery inherent in the specific dynamic in order to make sense of the experience in their own terms. This openness provides a liminoid context in which new forms, images, identities, and behavioral patterns may be forged. Rather than functioning as a positive induction to new modes of thought or behavior, the dynamic provides experiences through which one might strip away, or learn to refrain from, habitual modes. Thus, while entering alternate modes of consciousness might be an immediate tool within the dynamics (giving access as they do to deeper levels of imaginative and unconscious material), the dynamics might also be seen to initiate alternate modes of being, that is, more permanent behavioral changes.

Turner recognized theatre as an 'inheritor' of ritual, potentially capable of fulfilling some of the latter's reflexive, liminoid, and transformative functions, but requiring, if it is to do so, 'power sources' which are 'often inhibited or at least constrained in the cultural life of society's "indicative mood" (1990: 12). Núñez's theatre involves a number of the routes to power which Turner identifies: the body-use of energetic positions derived from ritual practices; long-durational actions that raise endorphin levels; meditative techniques; and driving techniques of the kind identified by Eugene d'Aquili and others (d'Aquili et al. 1979), for example, in the use of drumming, vibratory chanting, and rhythmical repetitive actions. Indeed, it could be argued that the main thrust toward 'power' lies in the use of such techniques to bring about a unified presence in the here and now. Meditative techniques in this work are performed within and through physical actions; physical actions are accomplished via meditative focus; driving techniques themselves are identified as a means of harmonizing bodily rhythms. Thus in all cases we might identify these techniques as means by which to bring disparate aspects of the whole being into harmony. This is in itself a central means of tapping into power within the self - accessing energetic and psychological potentials that are normally beyond our immediate grasp. Centrality in the self and in the moment coupled with the motivating, arousing, and reflexive potentials of the epic struggle empower individuals to go beyond their habitual limitations within a context that is at 
once imaginal and actual. Transformation is, theoretically at least, possible on psychological, emotional, and physiological levels.

Within Tonatiuh, Citlalmina, and the other dynamics, I believe it is possible to identify a series of practical objectives that effectively act as a kind of ladder - each rung facilitating access to the next. The participant's attainment of each rung is also an important end in itself since it is the attainment of a level of psychophysical development. This structure is reminiscent of the ritual 'ladders' of certain religious practices; for example, the seven chakras of Tantric Kundalini yoga through which the yogi progresses, cultivating at each stage a more developed form of consciousness and psychophysical presence. As with the chakras, each rung in Núñez's dynamics leads to the next, but like the Hasidic ladder to Heaven, one can also reach enlightenment at any stage by a jump in consciousness.

The first rungs of work within the dynamics comprise the epic struggle. Participants are encouraged to: (1) silence the rational mind and banish distracting thoughts-perhaps using a mantra, creative visualization, or rhythm to assist in controlling the mind's tendency to wander; (2) be present in the here and now, avoiding thoughts of past or future, and focus on the somatic sensation of one's bodymind within the particular spatial experience; and (3) focus physical and mental energies, and work with the image of raising and controlling energy through the psychophysical actions. These three challenges go hand in hand, the attainment of one helping the participant to progress with the others. When the intellectual properties of the rational mind, which serve to distance us from reality by 'interpreting' it, are temporarily silenced, a more intuitive and immediate mode of consciousness emerges. In this state we can begin to directly inhabit our own experience, to experience ourselves fully in the here and now. Given that in daily life we are mostly accustomed to mental withdrawal from the present moment (thinking forward or backward in time, but rarely focusing on the present), the attainment of this state, which Núñez calls 'the actualized instant' (1996b) is an empowering and energizing experience in which we feel our mental and physical resources to be fully activated. 


\section{Tonatiub (1984)}

Of the 21 dynamics which the TRW currently utilizes, two provide a particularly fruitful source for analysis and discussion. Tonatiub (Tonn-ah-chew; 1984), the oldest of the dynamics, is the simplest to learn and the one in which meditation in motion is most clearly discernible. Citlalmina (Seet-lalmeen-ah; 1988) is the most complex of the dynamic structures, and the best example of psychophysical cultivation by means of 'deconditioning'.

Since the action in Tonatiub is broken down into clearly defined sections, each of which comprises a single psychophysical activity, it can quickly be understood by simply following the instructions of the leader. Each activity is accompanied by a simple meditation, which is also easily explained and incorporated. This is of great importance to Núñez since his work is designed for theatrical and workshop situations in which it is desirable to have exercises that participants can experience after a minimal induction. Nevertheless, full embodiment and, particularly, full mental presence are cultivated only through repetition over time.

\section{TONATIUH}

External Score

lying on the back

sitting

slow walking

contemplative running

whirling

vibration: vocalization and playing of conches; rhythmic group action with drum and rattles; closing circle

\section{Internal Score}

meditate on all that is mineral within you meditate on all that is vegetable within you meditate on all that is animal within you meditate on all that is human within you meditate on all that is divine within you focus is now brought to the self as a whole, and to the group as a whole - the sense of communal experience is heightened in these final three sections 
In this dynamic, activity is gradually elevated from a supine state to sitting, and then slow walking. In the TRW's version of slow walking, the participant aims to move as slowly and smoothly as possible, taking exaggerated steps so that there is a maximum of activity in the muscles of the supporting leg. The participant's attention is quickly drawn to balance, and to her shifting center of gravity as she moves slowly forward in space. The pace of the walk has a calming effect and breathing is slowed and harmonized accordingly. Throughout the walk, the participant must ensure that her attention is not allowed to wander but instead is fluidly fixed upon the sensation of the body in motion, and upon the imagery that arises from the instruction, 'meditate on all that is animal within you'.

On a given signal, participants gently transform the slow walking into 'contemplative running'. Also referred to as the 'contemplative trot', this run functions as a dominant tool in almost every dynamic (with the notable exception of Citlalmina). Núñez developed the contemplative run while working with Grotowski on Theatre of Sources in 1980, as a form of meditation in motion: a means of focusing and quieting the mind, and at the same time centering consciousness on somatic experience. Within the dynamics, the run is also instrumental in forging a sense of group rhythm and communal activity. Núñez describes the tool in Anthropocosmic Theatre:

[W] e trot floating through the area, relaxing at every step, avoiding the tension in the arms which one gets in a running race, and do not try to advance, since there is nowhere to reach and nobody to beat. We keep our look open, i.e., without focusing, and the same goes for our active internal chant; we must feel that we are hanging by a thread which comes from the crown of our head and is tied to the stars, and flow at our own pace in a constant here and now (p. 119 above).

Most significantly, the continual movement of the contemplative run is achieved only through an equally continual effort of the mind. The runner 
must struggle to achieve 'mental polarization', the focusing of the mind's energies on the run itself. As the participant runs, she encounters, moment by moment, the tendency for the mind to wander, the desire to let the body give in, the craving to be in another place, at another time. Artaud wrote at length about the inability, as he perceived it, to inhabit his own existence, to achieve 'constant concert' (1968: 40); in Núñez's work, participants run into their own lives, run to find themselves. As Ronald Grimes has pointed out in his analysis of Grotowski's Theatre of Sources, statements such as this are often interpreted as pointing toward a narcissistic introversion on the part of the participants. In light of this, Grimes suggests that Grotowski's term 'work on oneself' is better phrased as 'work as oneself' ([1982] 1995: 181). In Núñez's work also, 'finding oneself' is achieved not through self-oriented deliberation, but through heightened awareness of one's own psychophysical presence. Thus, the contemplative run is not contemplative in the sense that one contemplates ideas while running. Rather, it is contemplation in the sense of meditation, a total focus of the mind on the body, on the experience of the run. As Claudio Naranjo has suggested, meditative practices involve the cultivation of a state that is markedly different from 'normal' activity and 'normal' consciousness:

While in most of one's daily life the mind flits from one subject or thought to another, and the body moves from one posture to another, meditation practices generally involve an effort to stop this merry-goround of mental or other activity and to set our attention upon a single object, sensation, utterance, issue, mental state, or activity (in Naranjo and Ornstein 1972: 10).

Meditative mental focus requires, and cultivates, what Naranjo calls 'a sustained openness to the present'; one cannot turn away from one's immediate experience, the challenge is simply to face it. In the dynamics, the primary task is to experience the moment fully and directly, without the interference of a distancing rationality. While running, you cannot think of 
running 'somewhere'; there is no goal to reach. This is one distinction between contemplative running and athletic running, and it is of essential importance. Participants do not think ahead of themselves any more than they think of past events; they focus here and now-not running to, and not running for, just running. In this sense of 'goallessness', it is similar to other meditative practices, such as zazen, or Zen sitting, as analyzed by Grimes: 'Zazen is not a preparation for anything, even enlightenment. There is no difference between practice and goal [...]. One's goal is to sit without goals' ([1982] 1995: 94).

There is no difference between practice and goal; the running is all there is. In my own experience, I found that any thought of an arrival while in the contemplative running brought with it the danger of a complete relapse into habitual modes of being. Only in abandoning the notion of goal, arrival, achievement, or finish line, does one begin to inhabit the experience for itself. As with Grimes's description of zazen, I found the long periods of contemplative running 'excruciatingly painful'; the mind did indeed want 'to fly, or fill up' ([1982] 1995: 94 - 95), to sidestep the problems of 'polarization', staying still with nowhere to go. Eugen Herrigel's description of his Zen apprenticeship in archery includes an account of this difficulty:

As though sprung from nowhere, moods, feelings, desires, worries and even thoughts incontinently rise up, in a meaningless jumble, and the more far-fetched and preposterous they are, and they less they have to do with that on which one has fixed one's consciousness, the more tenaciously they hang on (1985: 53).

So it is in the contemplative run, and in other tools of the TRW such as slow walking; participants continually encounter their inability to simply be in the present moment. However, persistently making the required psychophysical effort (which, of course, may be a withdrawal from 'effort'), without thought of reward, may indeed bring rewards. Phillip Zarrilli has identified the sense of 'presence' that can be achieved through psychophysical practices whereby the energetic "blazing flame" of an active, inner, vibratory perceptivity' is 
apparent to a spectator (1997: 109). The dilation of energetic presence may be accompanied by a dilation of self-awareness; the runner comes to new understandings about the self, about his weaknesses, habitual tendencies, willpower, fears, etc. Energetic flow within the body, and the places where that flow is blocked or misdirected, become apparent to the mindful participant. Further, the experience of focusing the mind, and quieting mental chatter may lead to a state of nondual awareness, and with this, a different form of perceiving and experiencing.

Etzel Cardeña, a psychologist and theatre practitioner who has researched and published widely within the field of altered states of consciousness, has described his experience of nondual consciousness in relation to Núñez's practice:

Dual consciousness is one in which your consciousness is separate from your body, separate from others, separate from the surrounding environment. While working [with Núñez and similar practitioners] this separate dual consciousness starts breaking down at times. [...A] one point there will be no observing self that is separate from the action that is occurring. [...I]f there is a movement that has to happen [..., instead of a thought preceding the action there is a consciousness in action, or an action in consciousness (1998: $n p)$.

In this state, participants experience both a unified sense of mind and body, and also a sense of the intrinsic unity of self with others, with the world around them, even with the cosmos itself. The run becomes effortless, a sensation of space opens up in the mind, and a feeling of calm, high energy, perhaps ecstasy, pervades.

Tonatiuh is one example of a dynamic that employs a ludic strategy of imaginal association. The imaginal and energetic force of 'as if', which Stanislavski identified at the heart of theatre, is, for Núñez, a key element in moving from the domain of theatre to that of its near relative, ritual. In Tonatiuh, by addressing that which is mineral, vegetable, animal, etc., within them, participants make imaginative leaps, approaching the task in the way 
that is most meaningful for them personally. In other dynamics, participants might similarly evoke imaginal environments, animal guides, or representations of natural forces. And in all of Núñez's work, theatrical games are played as if they were real; as Núñez would say, we play 'with the seriousness of a child' (1999).

Turner has described this 'subjunctive' mood of 'as if', in which both theatre and ritual exist: 'Subjunctivity is possibility. It refers to what may or might be. It is also concerned with supposition, conjecture, and assumption, with the domain of "as-if" rather than "as-is" (1983: 235).

As a meditative and somatic exploration of images of the self as mineral, plant, animal, and divinity, Tonatiuh provides participants with an imaginal experience of oneness with nature and the universe. While the concept that humans are an integral and continuous element within a cosmic whole is derived in Núñez's work from ancient indigenous Indian practices, a similar philosophical position is expressed by Meister Eckhart of the European mystical tradition: 'The soul is all things. She has being with the stones and growing with the trees and feeling with the beasts and understanding with the angels' (in O'Neal 1996:86).

In Tonatiuh, participants simultaneously encounter themselves as complexes of physiological and psychological weakness and resource, and as imaginal beings mythologically interconnected to a universe of elements and energies. Eckhart, here, is expressing that unio mystica which meditative and mystical practices aspire to, while Tonatiub is an imaginal game, a 'metaphoric identification' (Grimes [1982] 1995: 257) more likely to shed light on the participant's individual psyche than to produce a mystical experience.

\section{Citlalmina (1988)}

In contrast to the simple structure of Tonatiub, Citlalmina comprises a complex corporeal alphabet; whereas one can be fully engaged with Tonatiuh on a first encounter, Citlalmina can be learned only through extensive practice. The complexity of the form raises challenges different from those 
of the simpler dynamics, while the central premises remain the same. Citlalmina may be seen as the TRW's warrior rite par excellence, as a highly effective transformative ritual, and as a vehicle for developing mental focus and energetic control. This ritual dance was born of the TRW's research in Náhuatl and Tibetan cultures, and is the marriage of a warrior dance from each tradition - a Mexican Náhuatl conchero shell dance (danza conchera), and the Tibetan 'Black Hat' dance (Lha-lhung Pay-dor). It has been officially recognized and authorized by the religious authorities from each tradition: by General Teresa of the concheros, and by the Dalai Lama who blessed it as a 'tool for mental training' (p. 137 above). ${ }^{27}$

In Citlalmina, neither of the source dances is interfered with, nor are they combined, but rather placed next to one another; the upper-body fluidity and lightness of the Tibetan dance in its entirety is nested between cycles of the Mexican dance with its powerful, grounding, step-based actions. Both dances are performed in circles, moving in a clockwise direction. Together, as Citlalmina, the sequence takes about one hour to perform.

Núñez tells us that the two sacred dances of which Citlalmina is formed are each 'ancestral tools to develop our attention and concentration' (p. 136 above). In performing the corporeal alphabet of Citlalmina, participants must adhere to two principal instructions:

Keep our internal attention alive, tuning it to our breathing, without allowing the mind to wander; Flow with the mandalic design which completes the dance at an organic rhythm, which helps us to keep our attention on the here and now (p. 135 above).

Thus, Citlalmina is structured to support the psychophysical demands of meditation in motion through such methods as repetitive aural rhythms, changing physical rhythms, complex actions requiring close attention, and circling and

27 For a discussion of Citlalmina as a translation from Vajrayana Buddhist practice, see Middleton and Plá (2018) 'Adapting the Dharma: Buddhism and Contemporary Theatre Training,' Journal of Global Buddhism Vol. 19 (2018): pp. 113-125. 
crossing actions. The body alphabet itself comprises movements that have the effect of 'deprogramming' the bodymind, thereby allowing the harmonizing of mental and physical energies and the dissolution of habitual psychophysical blockages. The deprogramming or deconditioning actions work against daily, habitual physical processes, for example, left- or right-handedness, and forwardmotion.Circling, stepping, whirling, and the simple yet confounding combination of directional turn and sided action in, for example, the step called Quetzalcóatl, all have the effect of disrupting physical expectations. Movement becomes less automatic, and physical awareness is resensitized. Nonhabitual actions also have the effect of awakening muscular and emotional responses that may otherwise have lain dormant, thus influencing participants' subjective experiences of their own bodyminds. As with other bodymind practices, participants are enabled to see themselves anew within the frame of the unfamiliar, becoming aware of conditioned, habitual, and detrimental uses of the self. As Naranjo tells us in relation to meditative practice:

What the meditator realizes in his practice is to a large extent how he is failing to meditate properly, and by becoming aware of his failings he gains understanding and the ability to let go of his wrong way. The right way, the desired attitude, is what remains when we have, so to speak, stepped out of the way (in Naranjo and Ornstein 1972: 9 - 10). In texts on the Theatre of Sources-a project that Núñez and Guardia were involved with for one year-Grotowski spoke of the suspension of 'daily-life techniques of the body' as a means by which to bring about the 'deconditioning of perception':

Habitually, an incredible amount of stimuli are flowing into us [...] but we are programmed in such a way that our attention records exclusively those stimuli that are in agreement with our learned image of the world. In other words, all the time we tell ourselves the same story. Therefore, if the techniques of the body, daily, habitual, specific for a precise culture, are suspended, this suspension is by itself a 
deconditioning of perception (1997: 257 - 258).

For Grotowski, such a deconditioning-which he refers to elsewhere as an 'untaming' (in Kumiega 1987: 229)—returns us to the state of the 'Beginner' (229), that is, childlike immediacy and vibrancy of experience. Presence in the here and now is heightened, perception sharpened, and consciousness expanded; we escape from the 'prison' of our own 'babbling' (Grotowski 1997: 254), that internal monologue which suspends us between the past and the future, and insulates us from the present moment.

While, over time, repetition of any of the TRW's dynamics provides participants with the opportunity to cultivate their bodyminds in action, the pre- cise external form of Citlalmina represents the challenge to conform to technique and to discover one's own inner processes through a set external form. However, while Citlalmina consists of a complex corporeal alphabet, it is not taught by Núñez in such a way as to involve strict adherence to specific features such as alignment, center of gravity, etc. Although, clearly, the accomplishment of energetic positions in their finest detail will bring about specific and positive psychophysical states and experiences, here the emphasis is more firmly placed on the overall process, and on attention to one's mental journey through the process.

Grotowski considered that there were two ways in which to approach the state of Beginner: either through training in a technique or through 'untaming', as mentioned above (see Kumiega 1987: 229 - 230). Núñez has largely followed the latter route, stressing individual response and responsibility, and encouraging participants to find their own way of performing set actions, rather than following prescribed routes. The dynamics tend to function more as structures than as set sequences, and it is common to see great variation in the style, energy, and pace of any given action even among the most experienced members of the TRW. Citlalmina involves a significantly more detailed and complicated structure, but it is still, importantly, one in which each participant finds her own feet, so to speak. This has several positive effects, among them a sense of liberation 
and the creation of a nonjudgmental atmosphere for participants, and the displacement of attention from external form to internal discipline. It also means that Citlalmina remains an experiential activity and not an aesthetic spectacle. Perhaps it could be said that while training in a specific form one's mental activity is focused through attention to external form, in Citlalmina and the other dynamics one's physical activity is accomplished and dilated through attention to internal presence.

\section{Cura de espantos (1998)}

Throughout the long history of the TRW, the work of researching and creating actor-training dynamics has been accompanied by the work of creating participatory theatrical productions, exploring and experimenting with the ways in which theatre can be used as a matrix for ritual activity. In 1998, the group produced Cura de espantos, which translates, awkwardly, as something like 'Cure for Fears'. According to the theatre critic and playwright Victor Hugo Rascón Banda, the piece successfully employed theatrical and ludic elements as a springboard from which to move beyond the bounds of representation: 'Theatre is the path taken', he tells us, but 'What at first seems like a game, turns into an impressive, unforgettable experience. [...] Is Cura de espantos theatre? It must be. [...] Is it a religious act? It is that, too, due to its deep spirituality' (Rascón Banda 1998: 39).

Cura de espantos is designed for an outdoor, woodland setting-in Mexico City it was performed in the ancient forest of Chapultepec - and comprises a journey to the underworld, inspired equally by Dante and by the myth of Quetzalcóatl. The journey begins with the audience being blindfolded and then led deep into the forest by the TRW's monitors (guides who construct and manage the participants' experience). This induction provides an effective means of crossing a threshold from the real world, to the world of 'as if'. Further, the experience of being led blindfolded encourages an immediate introspection and self-reflection on the part of the individual. Thus, when the blindfolds are removed and the audience members find themselves deep 
within a fairy-tale forest, there is a clear sense that this will be an experiential form of theatre, with personal implications for its participants. In the forest, the participants encounter four lone figures; each performs a monologue, expressive of archetypal human concerns in answer to the question, 'What is your story?' Drawn mostly from Shakespeare, but also from de Sade, Dante, Calderón, Náhuatl poetry, and other texts, the performances epitomize areas of common existential conflict: self-doubt, anger, jealousy, lust. The four figures wear chains as a reminder of the extent to which our unresolved human passions can imprison us. It is clearly the intention of the TRW that spectators identify with one or more of the figures, and furthermore, that they reflect on the significance of the material in relation to their own lives. In order to facilitate this, the TRW includes an unusual and highly significant space in the performance- a space for self-reflection. For a few minutes, the actors and monitors leave the audience entirely alone in the forest, with the instruction that it is a time for silence and personal contemplation.

It is from this point of recognition and self-reflection that the theatrical event opens up to the participant an opportunity to begin the work of 'working on oneself', 'working as oneself'. The next stage of the experience is a 'rite' developed from a Náhuatl cleansing ritual in which members of the TRW have been initiated (and which is shared with the permission of the religious authorities). For Rascón Banda, this is 'the most interesting, emotive and disturbing part' of the experience, 'and closest to the postulates of anthropocosmic theatre' (1998: 57). Here, audience members are invited to participate in contemplative running and in a simple, rhythmical dance; to make contact with the earth, and with themselves; and to enact a gesture of forgiveness - first, forgiving another member of the audience for 'whatever they have done', and then forgiving themselves. The assumption is that we free ourselves of unhelpful emotional constructs when we learn to accept ourselves and to forgive ourselves for the events that have damaged and limited us. The ritual actions serve as an opportunity to enter into an imaginative act of self-acceptance and self-liberation. The rite builds upon a foundation 
of emotional and imaginative readiness that has been created through the earlier parts of the performance. Having been touched, and perhaps troubled, by identification with the performed sections, audiences seem eager to participate in the physical actions of running, etc., and this in turn further involves them in an acceptance of the interior workings of the ritual.

I experienced Cura de espantos in Mexico City in May 1998, and afterward wrote this:

My mind turning alone in the still moment in the forest cannot find a path, but in movement we raise other energies, we run into the here and now. I look into my partner's eyes: the look of I and Thou that Martin Buber wrote of, which transforms the other into a holy being, in which we recognize the humanity, the tenderness, of the other behind their daily garb. I touch my partner's heart and I forgive him for whatever has caused his pain, his fear. It's a simple trick, for having made my best effort to forgive him with all sincerity, I am invited to forgive myself. And if I can forgive him, why not forgive myself? (1998).

If this ritual is effective for its participants, then it is because the theatrical journey has first of all brought us to a point of recognition. We recognize our own need for emotional or spiritual change, and we are offered a ludic means of transformation. Significantly, the rite of transformation is itself both physical and contemplative, both communal and personal, both social and cosmic in its references.

Rituals of transformation, however, are not usually produced in isolation from supporting belief systems, communities, and ongoing ceremonial structures. Is the potential for meaningful personal transformation really within the scope of a theatrical game such as Cura de espantos? For Rascón Banda, Cura de espantos moves beyond the confines of theatre and achieves the status of ritual:

[The TRW] achieves a genuine communion between the participants and nature, the earth, their atavistic roots [...]. Spirituality is reached [... and] an encounter takes place with the spirit, meditation in silence and 
the quest for one's roots [...]. In an imposing silence, the participants hug the earth, are purged and discover the light which illuminates the way back to their starting point (1998: 39).

Thus, for Rascón Banda, the experience itself creates a temporary but profound communitas, and provides archetypal symbols and enactments that serve to provide us not with doctrine or a specific set of beliefs but rather with a numinous contact with nature, and with the self.

I would suggest that for many contemporary, alienated individuals, uninhibited exploration of the states and actions offered by the TRW is a mode of being that requires cultivation over time. Nevertheless, in my own experience of witnessing several performances of Cura de espantos, I was struck by how very frequently participants appeared to let down their defenses, to become more wholehearted and less inhibited during the running and other actions, and to make genuine and compassionate contact with one another in the forgiveness rite. Further, if an individual participant cannot fully engage with the ritual during his first encounter with it, he may, at the very least, have equipped himself with some new ideas and experiences relating to his personal growth. After my first experience of Cura de espantos, I came away with a strong sense of having been given the tools with which I might continue my own process of transformation. In my journal, I wrote:

In the fairy tale, the adventurer is often given magic gifts, and here they are: the 'here and now', given in the running; the 'other', given in the looking; 'Mother Earth', given in the embrace with her; and of course my 'Self', returned to me in the forgiveness (1998).

In Cura de espantos, as in Núñez's dynamics, the participant has access to 'technologies', which can be employed beyond the confines of the immediate performance or workshop. These are, specifically, tools that allow us to make active psychophysical contact with mythological symbols as we might encounter them in ancient stories, ritual enactments, the natural environment, or daily experience. And it is precisely through such an opening of consciousness 
toward mythology that Núñez's work can attempt to function as ritual.

\section{Between Theatre and Ritual}

Núnez sees all of the work of the TRW as following a structure of: Theatre $\rightarrow$ Epic $\rightarrow$ Myth $\rightarrow$ Ritual [see Figure 11 on p. 270 below]. We have already discussed the epic proportions of the work, and we might see that it is this struggle, this warrior's battle, perhaps even 'sacrifice' in the Grotowskian sense of revealing oneself through a process of stripping away 'life masks' (1968), that allows the theatre format to support the transformative potentials traditionally associated with ritual. Through struggle, effort, strong energy, and willpower, the individual participant may begin to find that which is beyond the daily experience for most of us. When we go beyond the epic struggle, we come to a level of experience that Núñez describes as 'mythic'. That is, the epic challenges of the work bring us to a state of consciousness in which we can work meaningfully with archetypal, mythological imagery.

Núñez's theatre has been greatly influenced by his readings of Carl Jung, Joseph Campbell, and other mythologists, and it is, in great part, a desire to explore mythology and symbolism that motivates him: [T] he myths are really a deep, inner, and beautiful fruit for the human soul. So I think that our dynamics can give [participants] the possibility [...] to search for their own roots' (1993). In the dynamics, and in the participatory sections of the theatre productions, Núñez utilizes actions that allow participants to embody images and mandalic designs relating to mythic source-ideas and images. Mythology is actualized through the participants' active psychophysical engagement with images that assist them in the epic struggle required to achieve personal transformation and the experience of nondaily perception and consciousness. For the TRW, working as they are with theatre as the point of departure, presence in the fleeting moment becomes both the means by which participants can holistically engage with the imaginal world of myth, and also the experience to which mythology may bring us. Thus, participants experience rather than think about the meanings embodied in the myths. Anthropocosmic Theatre, then, might be 
described as a kind of mythology in action.

Turner paraphrases Lévi-Strauss's identification of myths as encapsulations of the problem of reconciling the dualities with which we live: problems such as 'life and death, good and evil, mutability and an unchangeable 'ground of being,' the one and the many, freedom and necessity' (1983: 231). The multiplicity of meanings inherent within mythological images and storystructures allows us to experience dualities in such a way as to undermine apparent contradictions in the face of meaningfulness on an a-rational level. And rituals provide an opportunity to physically embody the workingthrough of the mythic image or situation. In the dynamics and theatrical productions of the TRW, contact with the mythological image both empowers participants to make an epic struggle, and also provides access to alternate means and modes of understanding the universe. Through specific actions, and through the psychophysical experience of the mythic imagery and inherent concept of a particular piece of work, participants may begin to move into a different experience of 'understanding'. At this level, they may arrive at knowledge that is beyond the self, may even negate the notion of self. Each turns outward toward the group, the world, the cosmos, so that individual focus moves from introspection to full awareness of others. Only when intention is correct in the ways outlined above does the action become more than action; only then does the dynamic cease to be theatre and truly become rite. Thus, for Núñez, the journey from theatre to ritual is: Theatre $\rightarrow$ Epic $\rightarrow$ Myth $\rightarrow$ Ritual. Through the epic struggle and the mythic image, the dramatic structure of the dynamic becomes a vehicle to transport us into other realms.

For Núñez, theatre has the potential to support ritual processes, structures, and tools with which to interrogate the deep wisdom of the mythologies, and to activate our own latent psychophysical resources. As such, operating out of the base of a secular, cultural activity, Núñez's work moves into fields usually associated with religion: 'You can make a theatre of reflection, political theatre, personal theatre, whatever...but also, the theatre has the possibility to 
open the gates for you to see your situation in the cosmos' (1993).

Participants begin to 'see their situation in the cosmos' by experiencing themselves in relation to mythological imagery, and to mythological themes embedded in ancient corporeal codes and designs. The heightened sense of presence and the development of nondual consciousness bring with them an experience of our interconnectedness with the energies of the natural world, indeed the Universe.

Importantly, though, this is a spirituality that disregards doctrine. If Núñez's works can be described as rituals, then they are rituals of personal transformation within which each individual makes his or her own private journey. The work is clearly presented as a form of 'secular sacredness', and the practices are firmly rooted in the ludic context of theatrical games, 'serious games' (Núñez 1999).

This is a theatre in which we imagine that we are dancing the designs of the Universe, that we are making journeys in inner and outer space, that we are working to conquer those rebel parts of our bodies and minds that we may become whole. We imagine it, and in imagining it, perhaps we make it true. We touch the divine in ourselves and in each other when we run, metaphori- cally throwing off the garments of society, opening our eyes to the look of I-Thou from another, literally arriving at a sense of the self as we begin to understand that there is no arrival, and that we are already here.

\section{REFERENCES}

d'Aquili, Eugene, et al. (1979) The Spectrum of Ritual. New York: Columbia Press.

Artaud, Antonin ([1956] 1968) Collected Works. Vol. 1. Translated by Victor Corti. London: Calder \& Boyars Ltd.

Cardeña, Etzel (1998) Interview with author. Huddersfield, England, 13 December.

Grimes, Ronald ([1982] 1995) Beginnings in Ritual Studies. Columbia: 
University of South Carolina Press.

Grotowski, Jerzy (1968) Towards a Poor Theatre. Holstebro: Odin Teatrets Forlag.

Grotowski, Jerzy (1995) 'From Theatre Company to Art as Vehicle' in Richards, Thomas, At Work with Grotowski on Physical Actions, London: Routledge, pp.115-35.

Grotowski, Jerzy ([1980] 1997) 'Theatre of Sources'. The Grotowski Source Book, edited by Richard Schechner and Lisa Wolford, 250 - 268. London: Routledge.

Herrigel, Eugen ([1953] 1985) Zen in the Art of Archery. Translated by R.F.C. Hull. London: Arkana.

Kumiega,Jennifer ([1985] 1987) The Theatre of Grotowski. London: Methuen.

Lendra, I Wayan (1991) 'Bali and Grotowski: Some Parallels in the Training Process'. TDR 35, 1 (T129): 113 - 39.

Middleton, Deborah K. (1998) Unpublished manuscript.

Naranjo, Claudio, and Robert E. Ornstein ([1971] 1972) On the Psychology of Meditation. London: George Allen \& Unwin Ltd.

Núñez, Nicolás (1987) Teatro Antropocósmico. Mexico City: Árbol Editorial.

Núñez, Nicolás (1993) Interview with author. Mexico City, 19 November.

Núñez, Nicolás (1996a) Anthropocosmic Theatre: Rite in the Dynamics of Theatre. Translated by Ronan J. Fitzsimons. Amsterdam: Harwood Academic Publishers.

Núñez, Nicolás (1996b) 'Theatre As a Personal Rite'. Workshop at the University of Huddersfield, England, 26 - 30 October.

Núñez, Nicolás (1999) 'Theatre and Transformation'. Workshop at the University of Huddersfield, England, 6 - 10 April.

O’Neal, David, ed. (1996) Meister Eckhart, from Whom God Hid Nothing. Boston: Shambhala Publications, Inc. 
Rascón Banda, Victor Hugo (1998) 'Cura de espantos’. Proceso, 1 February: 57 Schechner, Richard ([1977] 1988) Performance Theory. New York: Routledge. Turner, Victor (1983) ‘Body, Brain and Culture’. Zygon 18, 3: 221- 245 Turner, Victor (1990) 'Are There Universals of Performance in Myth, Ritual, and Drama?' In By Means of Performance: Intercultural Studies of Theatre and Ritual, edited by Richard Schechner and Willa Appel, 8 - 18. Cambridge: Cambridge University Press.

Van Gennep, Arnold ([1908] 1960) The Rites of Passage. Chicago, IL: University of Chicago Press.

Zarrilli, Phillip (1997) 'Acting "At the Nerve Ends": Beckett, Blau, and the Necessary'. Theatre Topics 7, 2: 103 - 116. 